\title{
The Role of Complement in Host Defence and Immune Response
}

\author{
R. Burger
}

Dept. of Immunology, Robert Koch-Institut, BGA, Nordufer 20, 1000 Berlin 65, w. Germany

\section{INTRODUCTION}

The immune system might be compared with a domino: There are individual elements which have to interact in a certain sequence. The sequence might vary considerably, depending on the point of view of the given investigator. These crucial elements within the immune response include antigen, antibody, T- and B-lymphocytes, MHC, cytokines and the complement system. Complement is one example of those pieces which one could place very well in different steps within the sequence. It contributes in the preimmune phase to non-specific host defence and inflammation. Alternatively, complement might be regarded as an early component during the induction of the specific immune response and it acts also in final, i.e. effector phase of the immune reaction. Complement is clearly a major humoral defence system. It represents a kind of endegenous immunomodulator or immunoregulatory system. In the following, a short overview of this protein system is given focussing on the role of the complement protein C3. C3 clearly represents a crucial component within the complement system.

\section{ORGANISATION OF THE COMPLEMENT SYSTEM.}

There are two different pathways of complement activation (MüllerEberhard, 1988). The "classical" pathway is triggered by AgAb-complexes. It includes the components $\mathrm{C} 1, \mathrm{C} 4$ and $\mathrm{C2}$. $\mathrm{Cl}$ consists of three different subcomponents, Clq, Clr and Cls. The "alternative" pathway uses the components factor $B$, factor $D$ and $P$ (properdin). The alternative pathway is activated through a variety of substances, e.g. microbial components like LPS. Both pathways lead to the formation of c3-convertases, which have the ability to cleave $C 3$ at a defined molecular site. Subsequently, the protein $\mathrm{C5}$ is cleaved and thereby activated. The activation of $\mathrm{C} 3$ and C5 represents a central event within the complement system. The C3- and c5-fragments generated through the proteolytic cleavage are biologically highly active mediators. They have the capacity to bind to a variety of cell populations through specific receptors. Binding of the $\mathrm{C3}-$ or $\mathrm{C5}-$ fragments triggers cellular reactions. The cleavage of $\mathrm{c5}$ results in the formation of the membrane attack complex formed by consecutive interactions of the proteins $\mathrm{C5}, \mathrm{C} 6, \mathrm{C7}, \mathrm{C} 8$ and $\mathrm{C9}$. The resulting molecular complex C5b-C9 has the capacity to insert into the membranes of cells and forms transmembrane channels leading to lysis of the target cell. An up- to-date definition of complement includes in addition to the previously mentioned proteins more than ten additional, mainly regulatory 
active proteins and should include also functional aspects. The main functions of the complement system are listed in Table 1.

Table 1: Functions of the complement system

- handling of immune complexes

- host defence against infections

- inflammatory reactions

- regulation of the immune response

Complement is probably of major importance in the preimmune stage when antibodies are still absent. In this stage complement provides an

important contribution to the host defence. How does one learn about the functions of this system? Major evidence was obtained through the application of various in vitro systems (Böttger, 1987). However, most revealing are perhaps genetically controlled deficiencies of complement components as a kind of experiment of nature (Ross, 1984). Such

complement defects occur spontaneously with different frequency. In a very generalized-classification one might distinguish two different groups of genetic deficiencies as revealed by the consequences observed clinically. Deficiencies of the "early" components (Clq, Clr, Cls; C4; C2) generally lead to autoimmune phenomena and SLE-like symptoms. Deficiencies in C3 and the "late" components C5-C9 are generally characterized by bacterial infections.

\section{THE COMPLEMENT COMPONENT C3}

From its biological activities, the complement component $\mathrm{C} 3$ is probably the most important complement protein (Burger, 1987; Lambris, 1990). C3 activation is not only achieved by $\mathrm{c3-convertases}$ of the classical or alternative pathways. During tissue lesions or inflammatory reactions, proteases are released, which might directly activate $c 3$ by proteolytic action. In each case, the cleavage products $\mathrm{C} 3 \mathrm{a}$ and $\mathrm{C} 3 \mathrm{~b}$ are generated. Both, the anaphylatoxin $\mathrm{C} 3 \mathrm{a}$ and the major fragment $\mathrm{C} 3 \mathrm{~b}$, have biological activity (Bitter-Suermann, 1988). C3b has the capacity to bind to the surface of biological particles. Bound C3b can initiate further formation of the alternative pathway $\mathrm{C} 3$ - convertase through the binding of factor $B$ and activation by factor $\mathrm{D}$. The C3-convertase can lead in an amplification reaction to further cleavage of $\mathrm{C} 3$ and triggers the formation of the membrane attack complex. In the absence of activating surfaces, the generated $\mathrm{c} 3 \mathrm{~b}$ is inactivated through the action of a number of regulatory proteins present in plasma (H;I) or on the cell surface (e.g. CRI). The regulatory proteins inactivate C3b by further proteolytic cleavage at defined sites. This inactivation at the same time generates new c3b fragments which in turn are biologically active (Table 2).

The various functions mediated by $\mathrm{C} 3 \mathrm{~b}$ or its fragments are initiated through binding to specialized receptors on a variety of cell populations (e.g. CR1, CR2, CR3, C3a-receptor, C3e-receptor).

A biologically highly active molecule like c3b requires efficient control mechanisms. On the one hand, the generation of sufficient $\mathrm{C} 3$ fragments must be secured, on the other hand excessive c3-activation and potential damage to the tissue must be prevented. Therefore, the ubiquitous control proteins in the plasma or on the cell surface are of great importance. 
Table 2: Biological functions of $\mathrm{C} 3 \mathrm{~b}$ or $\mathrm{C} 3 \mathrm{~b}$-fragments

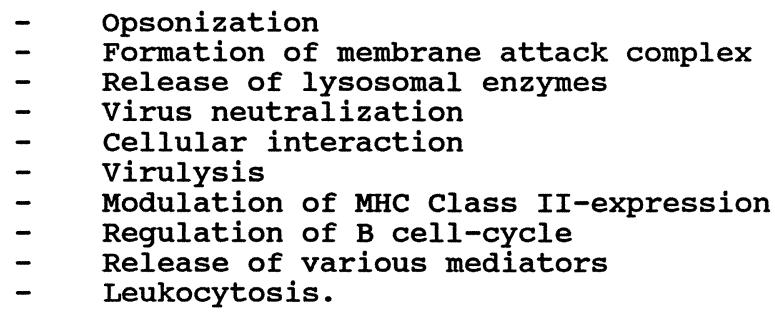

THE ROLE OF C3 IN THE SPECIFIC IMMUNE RESPONSE

Analysis of the role of $c 3$ in the induction of the specific immune response is an important topic and studies are performed in a number of laboratories (Böttger, 1987; Hartung, 1983; Hugli, 1990). Several different experimental approaches were used. In part, the results obtained were not compatible and subject to controversy. The general aproaches are listed in Table 3.

TABLE 3: Complement and immune response - Experimental systems

1. Complement depletion in vivo by cobra venom factor.

2. Anaphylatoxins or other fragments affecting the immune response in vitro.

3. B cell triggering by antibodies to complement receptors.

4. Complement.deficiencies.

The first hints on the role of complement in the induction of an immune response was obtained through studies in the murine system using cobra venom factor for depeletion of complement in vivo. These studies showed an impaired capacity for antibody formation to $T$ cell-dependent antigens after complement depletion. Subsequently, numerous studies were performed which revealed that purified complement fragments had the ability to influence immune phenomena in vitro. These studies were supported by an alternative approach namely the use of antibodies to complement receptors. These antibodies replaced the physiological ligand, e.g. C3b or its fragments and could trigger various cellular effects at the $B$ cell level. A critical evaluation of these approaches reveals several fundamental problems which complicate the interpretation. One example: Injection of purified cobra venom factor into the mouse does cause the desired depletion of $\mathrm{C3}$ and $\mathrm{C5}$, but at the same time the immunocompetent cells are exposed to high concentrations of the biologically highly active C3- and C5-fragments generated at the same time. These fragments might markedly affect the cellular reactivity. 
Genetically Controlled C3-Deficiency as In Vivo Model

For these reasons, genetic deficiencies provide a superior model because they allow analysis of the effect of complement components without artificial pretreatment or manipulation. Genetic deficiency of $\mathrm{C3}$ is in the human a rare event (Ross, 1984). In the literature there are less than 20 patients described. These patients show a markedly increased susceptibility to bacterial infections. They suffer under severe, recurrent infections including pneumonia, otitis, meningitis and septicemia. The serum bactericidal activity and the capacity for opsonization is reduced. Chemotactic activity is similarly impaired. The c3-deficient patients frequently show clinical symptoms of renal diseases, skin rash, arthralgia and circulating immune complexes were demonstrated (Schifferli, 1981).

Recently, we described as the first genetic deficiency of c3 in a small laboratory animal, a genetically controlled deficiency of $\mathrm{C3}$ in an inbred guinea pig strain (Burger, 1986; Bitter-Suermann, 1986, 1990). These animals provide an ideal model to control critically in an in vivo system the results of the various in vitro studies. The c3-deficiency was identified within a colony of inbred guinea pigs. These normal, complement-sufficient animals have therefore the same MHC and other genetic features as the C3-deficient animals and provide an appropriate control population. The c3-deficient animals are of particular importance if one considers the quite controversial results on the role of $\mathrm{C3}$ in vitro. One reason for this controversy might be the critical role of the assay conditions. The importance of the experimental details is emphasized e.g. in the studies of Melchers (1985) and coworkers using synchronized, anti-IgM activated B cells. In this system, the fragment c3d represents a growth or differentiation factor for the preactivated $B$ cells, if provided in a multimeric form, i.e. as Sepharose-bound c3d. However, if soluble, monomeric c3d was used, it did not increase but did inhibit the $B$ cell proliferation. The c3-deficient guinea pigs provide a system to analyse the role of $c 3$ in vivo without any artificial

pretreatment. They should provide an answer to the question which steps of the immune response are affected in the absence of $\mathrm{C3}$ or, similarly important, which steps are not affected in these animals.

In order to determine the role of $\mathrm{C} 3$ in the humoral immune response, we used initially the model antigen ex174 (Böttger, 1986). The animals were immunized on day 0 with a defined amount of ex174-antigen. The animals received a single booster injection at day 28 . Serum samples were obtained from the beginning in weekly intervals and the antibody titer was measured in a neutralization assay. The normal inbred strain 2 animals served as control. The C3-deficient animals showed a markedly impaired antibody response to this

$T$ cell dependent antigen $\theta \times 174$. There was a reduced formation of IgM antibody. Upon the booster injection, there was no switch from IgM to IgG observed and no amplification of the antibody titer occured. The impaired immune reactivity was partially normalized by immunizing with a high antigen concentration. Immunization with complete Freund's adjuvant did similarly normalize the antibody formation partially. When the c3deficient animals were reconstituted with normal $\mathrm{C3}$, the antibody response to $\mathrm{\theta x} 174$ was also partially normalized. However, in each case, the immune response was still markedly reduced compared to normal animals. 
A similar impairment was found when the antibody response to another $T$ cell dependent antigen, sheep red blood cells, was measured. However, if the antigen ovalbumin was used for immunization, no reduction in antibody formation was observed (Köhler, 1989). The ovalbumin response is probably no primary response; this protein is present in the guinea pig diet. The dependency on C3 might be most critical during a primary response and less obvious in a secondary response.

There are several plausible mechanisms through which the absence of c3 might affect the induction of the immune response.

a. The follicular antigen localization is known to depend on C3 as shown by depletion experiments with cobra venom factor.

b. In the absence of $\mathrm{C3}$, the proper immune complex handling might be affected resulting in a less efficient antigen uptake and presentation.

c. B cell stimulation might be affected due to the absence of the c3derived B-cell growth factors.

d. The generation of $B$ memory cells might be insufficient in the C3deficient animals.

e. The c3-deficiency might exert its effect not at the lymphocyte but at the macrophage level.

C3-fragments are known to modulate several macrophage functions e.g. the expression of MHC class II-antigens or the production of prostaglandins (Hartung 1983a, 1983b). Therefore, effects at the level of the antigen presenting cell, might also explain the reduced immune reactivity of the c3-deficient animals.

The molecular basis of the c3-deficiency in the guinea pig is still unclear. However, several possible explanations are eliminated meanwhile. Hepatocytes and macrophages of these animals have the capacity to synthesize and secrete c3-protein, measured as antigen, in vitro. A normal amount and size of C3 mRNA is found in liver cells of the animals (Auerbach, 1990). C3 purified from normal guinea pig serum is catabolized normally in the C3-deficient animals excluding therefore a possible defect of a regulatory protein, e.g. of H (Burger, 1986). Recently, the C3-gene of the normal and C3-deficient guinea pigs was cloned and sequenced (Auerbach, 1990). Only a few differences in the nucleotide sequence were identified which did not alter the deduced amino acid sequence. Therefore, there is no defect of the structural gene for c3. Recent findings indicate, that the posttranslational modification of C3 is affected in the C3-deficient animals (Auerbach, 1990). C3 synthesized in vitro by cells of the C3-deficient animals failed to incorporate methylamin. In addition, the autolytic cleavage inducable in normal c3 under certain conditions, did not occur in the c3-deficient animals. Both functions, methylamin incorporation and autolytic cleavage, depend on an intact thiolester within the $\alpha$-chain of C3. Apparently, some critical posttranslational steps are impaired in the C3-deficient animals preventing therefore the formation of this thiolester. The structurally aberrant $C_{3}$ seems to be cleaved in vivo rapidly by ubiquitous proteases. The thiolester ringstructure in the c3-alpha-chain is essential for the binding of $\mathrm{C3b}$ to biological structures and is required therefore for the various biological activities of $\mathrm{C} 3, \mathrm{e} . \mathrm{g}$. factor B-binding, activation of C5 etc (Levine, 1990).

As mentioned above, one plausible reason for the impaired immune response in the c3-deficient animals might be the failure to generate immunoregulatory $\mathrm{C} 3$ fragments. One of those fragments is the anaphylatoxin C3a known to be immunoregulatory active. 


\section{THE ANAPHYLATOXIN C3a}

C3a is low molecular C3-fragment (MW 9000 d). It belongs together with C5a and C4a to the group of the complement-derived anaphylatoxins (Hugli, 1984, 1986, 1990; Bitter-Suermann, 1988). C3a is a biologically highly active mediator and has the classical anaphylatoxin functions. It causes the contraction of smooth muscles, the release of histamin from mast cells, the release of serotonin from thrombocytes and an increase in vasopermeability. C3a induces the aggregation of granulocytes and the release of lysosomal enzymes. It inhibits antibody formation in vitro (Morgan, 1982; Weigle, 1983).

The anaphylatoxins recently gained considerable interest because they might contribute to the pathogenesis of the "adult respiratory distress syndrome" (ARDS) characterized by frequently fatal lung failure (Rinaldo, 1982, 1986; Lawley, 1984; Vogt, 1986; Chenoweth, 1986; Zilow, 1988). According to the "complement hypothesis", the anaphylatoxin C3a and C5a contribute to the pathomechanism of ARDS. The reaction sequence in ARDS is initiated by complement activation. This activation might occur through the alternative pathway (e.g. in sepsis) the classical pathway, (e.g. in serum sickness) or through proteases (e.g. in pancreatitis or in polytrauma patients). Through the complement activation the anaphylatoxins are generated and cause aggregation of granulocytes followed by the accumulation of these cells in the lung and local release of various mediators (e.g. oxygen derivatives, lysosomal enzymes, prostaglandins). These locally released mediators might be responsible for the observed tissue damage and vasopermeability increase leading to the fatal edema. The work of Hack (1987) showed that elevated c3a-levels are clearly associated with fatal outcome in sepsis. In this study, the mortality in sepsis patients with plasma levels below a certain concentration was in the range of $33 \%$. In contrast, the mortality in sepsis patients with a c3a-concentration above this limit was $86 \%$.

The three-dimensional structure of C3a is known from X-raycristallographic studies (Huber, 1980). The C-terminal portion of the molecule is responsible for the interaction with the c3a-receptor (Caporale, 1980). The reagent of choice for analysis of c3a function and receptor interaction are monoclonal antibodies directed against neoantigenic determinants of C3a because the ubiquitous native C3 would not interfere with neoantigen-specific reagents. The interference of C3 might also affect other in vitro studies. C3 is a major serum protein and is also synthesized in culture by macrophages. Initial attempts to produce monoclonal antibodies to neoantigenic determinants of C3a failed, probably due to the low molecular weight, the conserved structure between the species and its immunosuppressive effect. We described the first monoclonal antibody, i.e. to $\mathrm{C} 3 \mathrm{a}$ which did however recognize a conserved determinant present also on C3 (Burger, 1982, 1987; Klos, 1988).

\section{The Importance of Neoantigenic Epitopes of C3a}

We used an alternative approach for the production of a monoclonal antibody to a C3a-neoantigen (Burger, 1989). This approach might similarly be useful for other systems involving proteolytic activation steps. The following strategy was used: C3a is generated by cleavage between amino acids 77 and 78 of the $\alpha$-chain of $c 3$. The free c-terminus of C3a formed by this proteolytic event might represent a neoantigen because in the native $\mathrm{C} 3$ molecule these amino acids are "hidden" as a 
linear sequence. This free $\mathrm{C} 3 \mathrm{a}$ C-terminus is only present after activation of $\mathrm{C3}$, i.e. after C3a-generation. Monoclonal antibodies to this molecular site are of particular interest, because this is the area of the C3a-molecule which interacts with the C3a-receptor (Hugli, 1990). c3a is circulating in plasma as its c3a-desArg variant produced by removal of the c-terminal arginine in position 77 . Therefore, a octapeptide corresponding to the amino acids 69-76 of the C3a-desArg molecule was synthesized and linked to the carrier KLH. After immunization with these conjugate, monoclonal antibodies were produced. The hybrids were not screened against the conjugate but were tested for reactivity with C3a-desArg. Several antibodies were obtained with selectively reacted with C3a-desArg, but not with C3 in ELISA or Western blot (Burger, 1989). These neoantigen-specific monoclonal antibodies provided a tool to establish a novel system for the measurement of $\mathrm{C} 3 \mathrm{a}-$ desArg in biological samples (zilow, $1989 \mathrm{a}, \mathrm{b}$ ). In contrast to the conventional RIA, C3a-desArg is measured in this assay via an ELISA system. Therefore, no radioactively labelled $\mathrm{C} 3 \mathrm{a}$ is required. In addition, as a second technical advantage, due to the neoantigenspecificity of the monoclonal antibodies utilized in this ELISA no precipitation step for the removal of non-cleaved $C 3$ from the sample is necessary. This novel c3a-assay should facilitate clinical diagnostics, e.g. to monitor complement activation in patients at risk for ARDS or to measure complement activation induced by membranes in medical devices. In polytrauma patients C3a measurement by this ELISA provided a parameter with prognostic value (Zilow, 1989).

In addition to the diagnostic application (Dalmasso, 1986) the exquisite specificity of the monoclonal antibodies permits further analysis of c3a/c3a-desArg functions:

a. C3a-desArg was reported to induce IL-1 release from human monocytes (Haeffner-Cavaillon, 1987). This is one of the few functions associated with the C3a-desArg variant; in a number of other assay systems the intact $\mathrm{C} 3 \mathrm{a}(1-77)$ is required for functional activity. The ability of the monoclonal antibodies to distinguish between

C3a-desArg and C3a permits now to measure and influence functions associated with one of the c3a-variants only.

b. The monoclonal antibodies are directed against the receptor- binding c-terminus of c3a. According to the concept of "molecular mimicry" antiidiotypic antibodies to these C-terminus-specific monoclonal antibodies might react with the cellular binding site for C3a, i.e. the c3a-receptor. Antibodies to this poorly defined receptor structure for C3a on the various cell populations are not yet available. They would be of great importance for analysis of c3a-function in the inflammatory reaction or in the immune response.

In summary, C3 does not only contribute to nonspecific defence reactions like opsonization. It is obviously involved in the induction of the specific immune response. In addition, the $c 3$ fragments are major mediators of the inflammatory reaction. Finally, $\mathrm{C3}$ is a major element for the proper handling of immune complexes. C3 plays obviously a prominent role within the plasma proteins through its functional versatility. 


\section{REFERENCES}

Auerbach HS, Burger R, Dodds A, Colten HR (1990) Molecular basis of complement $\mathrm{C} 3$ deficiency in guinea pigs. $\mathrm{J}$ Clin Invest, in press.

Bitter-Suermann D, Burger R (1986) Guinea pigs deficient in $\mathrm{C2}, \mathrm{C} 4$ or $\mathrm{C} 3$ receptor. Progr Allergy 39: 134

Bitter-Suermann D. (1988) The anaphylatoxins. In: Rother $\mathrm{K}$. and Till G (eds) The Complement System, Springer, New York, p 367

Bitter-Suermann D, Burger R (1990) C3 deficiencies. Curr Topics Microbiol Immunol 153: 223

Böttger EC, Metzger S, Bitter-Suermann D, Stevenson G, Kleindienst S, Burger R (1986) Impaired humoral immune response in complement c3-deficient guinea pigs: absence of secondary antibody response. Eur J Immunol 16: 1231

Böttger EC, Bitter-Suermann D (1987) Complement and the regulation of humoral immune responses. Immunol today 8 : 261-264

Burger R, Deubel U, Hadding U, Bitter-Suermann D (1982) Identification of functionally relevant determinants of the complement component $\mathrm{C3}$ with monoclonal antibodies. $\mathrm{J}$ Immunol 129: 2042

Burger R, Gordon J, Stevenson G, Ramadori G, Zanker B, Hadding $U$, Bitter-Suermann $D(1986)$ An inherited deficiency of the third component of complement $\mathrm{C} 3$ in guinea pigs. Eur $\mathrm{J}$ Immunol 16: 7

Burger R (1987a) The complement component $\mathrm{C3}$ as a mediator of the inflammatory reaction. Progr appl Microcirc 12: 108

Burger R, Bader A, Kirschfink $M$, Rother U, Schrod L, Wörner $I$, Zilow G (1987b) Functional analysis and quantification of the complement $\mathrm{C} 3$ derived anaphylatoxin $\mathrm{C} 3 \mathrm{a}$ with a monoclonal antibody. Clin Exp Immunol 68: 703

Burger R, Zilow G, Bader A, Friedlein A, Naser W (1988) The $c$ terminus of the anaphylatoxin $\mathrm{C} 3 \mathrm{a}$ generated upon complement activation represents a neoantigenic determinant with diagnostic potential. J Immunol 141: 553

Caporale LH, Tippett PS, Erickson BW (1980) The active site of C3a anaphylatoxin. J Biol Chem 235: 10758

Chenoweth DE (1986) Anaphylatoxin formation in extracorporeal circuits. Complement 3: 152

Dalmasso AP (1986) Complement in the pathophysiology and diagnosis of human diseases. Crit Rev Clin Lab Sci 24: 123

Hack CE, Nuijens JH, Felt-Bersma RJF, Schreuder wo, EerenbergBelmer AJM, Paardekooper J, Bronsveld W, Thijs LG (1987) Elevated plasma levels of the anaphylatoxins C3a and C4a are associated with a fatal outcome in sepsis. Amer J Med 86: 20-26

Haeffner-Cavaillon N, Cavaillon JM, Laude M, Kazatchkine MD (1987) C3a (C3a-desArg) induces production and release of interleukin 1 by cultured human monocytes. J Immunol 139: 794-799

Hartung HP, Hadding, U (1983a) Synthesis of complement by macrophages and modulation of their functions through complement activation. Springer Semin Immunopathol 6: 283 
Hartung HP, Bitter-Suermann D, Hadding U (1983b) Induction of thromboxane release from macrophages by anaphylatoxic peptide c3a of complement and synthetic hexapeptide c3a 72-77. J Immunol 130: 1345-1349

Huber R, Scholze H, Paques EP, Deisenhofer J (1980) Crystal structure analysis and molecular model of human C3a anaphylatoxin. Hoppe-Seylers Z Physiol Chem 361: 1389-1399

Hugli TE (1984) structure and function of the anaphylatoxins. Springer Semin Immunopathol 7: 193

Hugli TE (1986) Biochemistry and biology of anaphylatoxins. Complement 3: 111

Hugli, TE (1990) Structure and function of C3a anaphylatoxin. Current Topics Microbiol Immunol 153: 181

Köhler V, Schäfer H, Kleindienst S, Stevenson G, Burger R (1989) The role of $\mathrm{C} 3$ in immune-response: analysis in C3-deficient guinea pigs. Abstracts, 7. Intl. Congress of Immunology, Berlin

Klos A, Ihring V, Messer M, Grabbe J, Bitter-Suermann, D (1988) Detection of native human complement component C3 and $\mathrm{C5a}$ and their primary activation peptides C3a and C5a (anaphylatoxic peptides) by ELISA with monoclonal antibodies. J Immunol Methods 111: 241-252

Lambris, JD (ed) (1990) The third component of complementchemistry and biology. Springer, Berlin, 1990

Lawley TJ, Bielory L, Gascon P, Yancey KB, Young NS, Frank MM (1984) A prospective clinical and immunologic analysis of patients with serum sickness. N Engl J Med 311: 1407

Levine RP, Dodds AW (1990) The thioester bond of C3. Current Topics Microbiol Immunol 153: 73

Melchers F, Erdei A, Schulz T, Dierich MP (1985) Growth control of activated, synchronized murine B cells by the c3d fragment of human complement. Nature 317: 264

Meuer S, Ecker U, Hadding U, Bitter-Suermann D (1981) Platelet-serotonin release by $\mathrm{C} 3 \mathrm{a}$ and $\mathrm{C5a}$ : Two independent pathyways of activation. J Immunol 126: 1506

Müller-Eberhard HJ (1988) Molecular organization of the complement system. Ann Rev Biochem 57: 321

Morgan EL, Weigle WO, and Hugli TE (1982) Anaphylatoxin mediated regulation of the immune response. I. C3a-mediated suppression of human and murine humoral immune responses. $J$ Exp Med 155: 1412

Rinaldo JE, Rogers RM (1982) Adult respiratory-distress syndrome, Changing concepts of lung injury and repair. $N$ Engl J Med 306: 900

Rinaldo JE, Rogers RM (1986) Adult Respiratory Distress Syndrome. New Engl J Med 315: 578-580

Ross SC, Densen P (1984) Complement deficiency states and infection: epidemiology, pathogenesis and consequences of neisserial and other infections in an immune deficiency. Medicine 63: 243-273

Schifferli JA, Yin CNG (1988) The role of complement in the processing of immune complexes. Baillieres Clin. Immunol. Allergy 2:

319-334

Vogt $W$ (1986) Anaphylatoxins: possible roles in disease. Complement 3: 177

Weigle WO, Goodman MG, Morgan EL, Hugli TE (1983) Regulation of immune response by components of the complement cascade and their activated fragments. Springer semin Immunopathol 6: 173 
Zilow G, Joka T, Rother U, Kirschfink M (1988) Anaphylatoxin generation in plasma and bronchoalveolar lavage fluid (BAL) in polytrauma patients. Complement 5: 200

Zilow G, Naser W, Rutz R, Burger R (1989a) Quantitation of the anaphylatoxin C3a in the presence of $\mathrm{C} 3$ by a novel sandwich ELISA using monoclonal antibody to a C3a neoepitope. J Immunol Meth 121: 261

Zilow G, Burger R, Naser W, Kleine TO (1989b) Indication for activation of the complement system in CSF during inflammation or haemorrhages of the CNS. J Clin Chem Clin Biochem 27: 929 